\title{
Activity of selected essential oils on spoiling fungi cultured from Marzolino cheese
}

\author{
Simona Nardoni ${ }^{1, A-F}$, Carlo D’Ascenzi ${ }^{1, A, F}$, Irene Caracciolo ${ }^{1, B, F}$, Gaia Mannaioni ${ }^{1, B, F}$, \\ Roberto Amerigo Papini ${ }^{1, F}$, Luisa Pistelli2,B,F, Basma Najar ${ }^{2, B, F}$, Francesca Mancianti ${ }^{1, A, C-F}$ \\ ${ }^{1}$ Università di Pisa, Dipartimento di Scienze Veterinarie, Pisa, Italy \\ 2 Università di Pisa, Dipartimento di Farmacia, Pisa, Italy \\ A - Research concept and design, B - Collection and/or assembly of data, C - Data analysis and interpretation, \\ $D$ - Writing the article, E - Critical revision of the article, F - Final approval of article
}

\begin{abstract}
Nardoni S, D'Ascenzi C, Caracciolo I, Mannaioni G, Amerigo Papini R, Pistelli L, Najar B, Mancianti F. Activity of selected essential oils on spoiling fungi cultured from Marzolino cheese. Ann Agric Environ Med. 2018; 25(2): 280-284. doi: 10.26444/aaem/80907
\end{abstract}

\begin{abstract}
Microscopic fungi can be present on a variety of foodstuff, including cheese. They can be responsible for fungal spoilage, causing sensory changes making food unacceptable for human consumption, and posing severe health concerns. Furthermore, some of these organisms are able to resist antimicrobial preservatives provided for by law. Antifungal activity of 15 chemically defined EOs, alone and in mixture, were checked by a microdilution test against isolates of Penicillium funiculosum and Mucor racemosus cultured from rinds of Marzolino, a typical Italian fresh pecorino cheese. Origanum vulgare yielded the lowest MIC values, followed by Salvia sclarea, Ocimum basilicum and Cymbopogon citratus, while Citrus paradisi and Citrus limon were not active. All mixtures showed antifungal activity at lower concentration with respect to MIC values of each EO component, when not in combination. This study is the first to describe the setting up of EOs mixtures to limit spoiling moulds.
\end{abstract}

\section{Key words}

essential oils, mixtures, cheese, spoiling fungi, Penicillium funiculosum, Mucor racemosus

\section{INTRODUCTION}

Italian cheese is one of the most appreciated symbols of the 'made in Italy' food products worldwide. This rich Italian tradition includes 52 PDOs/PGIs products (Protected Designation of Origin/Protected Geographical Information), over 237 registered in Europe, only in second place after France with 55 cheeses, and 492 further products registered as traditional cheeses by the Italian Ministry of Agriculture [1]. The cultural and economic value of this huge gastronomic resource is based on the quality of the raw materials used, and the need for excellence at all stages in the processing, interpreting the traditional methods, without additives or other chemicals.

Microscopic fungi such as moulds and yeasts are ubiquitous organisms, colonizing a broad variety of foodstuffs, including cheese. A wide diversity of fungal species can be present on these products, depending on the microbiota of the milk, on the handling processes and by organisms occurring in the productive and storage environments.

Most of these cheeses, in fact, are obtained through an ageing process that can be short, medium or long, in order to develop their unique attributes. During this period, spoilage by ubiquitous moulds can occur, representing a critical point in the production process. Moulds are important spoilage agents in cheese [2], affecting both colour and texture. These organisms can tolerate refrigeration temperatures and low levels of water activity, are able to grow on cheese rind, and some of them resist antimicrobial preservatives provided for by law, such as sorbate (Reg. 1333/2008).

Address for correspondence: Simona Nardoni, Università di Pisa - Dipartimento di Scienze Veterinarie, viale delle Piagge, 56124 Pisa, Italy

E-mail: simona.nardoni@unipi.it

Received: 13.06.2017; Acepted: 30.11.2017; first published: 23.01.2018
Essential oils (EOs) are mixtures of aromatic oily liquids extracted from different parts of plants, usually by steam distillation [3]. Several of them are characterized by antimicrobial activities, mainly due to their content in terpenes and phenylpropanoids $[4,5]$, and have been used both in therapy [6] and to control spoilage flora of foodstuff [7]. Natural plant materials have been used as food preservatives against both bacteria and fungi $[8,9]$. Consequently, natural mixtures have been added to a variety of foodstuff, including cheese, to control fungi producing visible fungal growth, off-flavours and/or mycotoxins [2]. Few data are available about the application of EOs for their antifungal activity in food such as cheese. To the best of the authors' knowledge, only two papers refer to the use of such compounds as mould inhibitors in the product $[10,11]$.

For these reasons, the aim of the presented study is to assess the antimycotic activity of some EOs against moulds spoiling Marzolino, a fresh, typical pecorino cheese from Tuscany, Italy.

\section{MATERIALS AND METHOD}

Fungal species employed in the present study were isolated from the rinds of Marzolino cheese showing an overgrowth of spoiling fungi occurring during ripening process. Fungal growth started from the first days post-ripening and increased until the end of the cheese maturation period (day 20), making the product unsuitable for sale.

Moulds were obtained as described by Samson et al. [12], with slight modification. Briefly, a $1 \mathrm{~cm}^{2}$ area of mouldy rind was collected by scraping with a sterile blade. Samples were dissolved in peptone water and homogenized using a Stomacher 80 (Pbi International, Milan, Italy). To achieve 
identifiable fungal colonies, a dilution plating technique was employed starting from $10^{-1}$ to $10^{-6}$, then $0.1 \mathrm{ml}$ of each suspension was seeded onto Potato Dextrose Agar (PDA). Plates were incubated at $25^{\circ} \mathrm{C}$ until a noticeable fungal growth was observed. Identification of fungal isolates was achieved by macro- and microscopic morphology. Results of morphological identification were confirmed by PCR $[13,14]$ and, when required, by sequencing.

EOs of Origanum vulgare, Ocimum basilicum, Foeniculum vulgare, Thymus vulgaris, Illicium verum, Syzygium aromaticum, Salvia sclarea, Origanum majorana, Rosmarinus officinalis, Citrus aurantium, Citrus paradisi, Citrus limon, Citrus sinensis, Citrus bergamia, Cymbopogon citratus were checked for their antimycotic activity. These products were selected for their proven antimicrobial efficacy and for their traditional usage in foodstuff preservation.

All EOS were kindly provided by Flora s.r.l. (Lorenzana, Pisa, Italy) and were chemically defined as reported below.

The MIC value of selected EOs was assessed by means of a microdilution test, starting from a 5\% dilution, following the method described by the Clinical and Laboratory Standards Institute M38A (CLSI 2008) [15]. EOs showing a satisfactory antifungal activity and derived from plants traditionally employed in artisanal cheese already present on the market, were selected to prepare 3 mixtures composed as follows: S. aromaticum, S. sclarea, O. vulgare, $1 \%$ each (M1), S. aromaticum, S. sclarea and C. citratus $1 \%$ each (M2) and C. citratus and T. vulgaris (M3) $1.5 \%$ each. To better understand the measurement of the effect of EOs combinations in the mixtures, the FIC Index (FICI) was calculated, as reported by Rosato et al. [16]. The FICI was interpreted as: (i) a synergistic effect when $\leq 0.5$; (ii) an additive or indifferent effect when $>0.5$ and $\leq 1$ and (iii) an antagonistic effect when $>1$. The fungistatic or fungicidal activities of EOs mixtures were evaluated re-seeding inocula in which noticeable growth was not present, after washing with saline, onto a fresh PDA.

The Gas Chromatography - Mass Spectrometry (GCMS) analysis were accomplished with an HP-5890 Series II instrument equipped with a HP-Wax and HP-5 capillary columns (both $30 \mathrm{~m} \mathrm{X} 0.25 \mathrm{~mm}, 0.25 \mu \mathrm{m}$ film thickness), working with the following temperature programme: $60^{\circ} \mathrm{C}$ for $10 \mathrm{~min}$, rising at $5^{\circ} \mathrm{C} / \mathrm{min}$ to $220^{\circ} \mathrm{C}$. The injector and detector temperatures were maintained at $250^{\circ} \mathrm{C}$; carrier gas, nitrogen ( $2 \mathrm{~mL} / \mathrm{min})$; detector, dual FID; split ratio 1:30. The volume injected was $0.5 \mu \mathrm{L}$. The relative proportions of the oil constituents were percentages obtained by FID peak-area normalization without the use of a response factor. GC-MS analyses were performed with a Varian CP-3800 gas chromatograph equipped with a DB-5 capillary column $(30 \mathrm{~m}$ X 0.25; coating thickness, $0.25 \mu \mathrm{m}$ ) and a Varian Saturn 2000 ion trap mass detector. Analytical conditions were as follows: injector and transfer line temperature, 220 and $240{ }^{\circ} \mathrm{C}$ at $3{ }^{\circ} \mathrm{C}$, respectively; oven temperature, programmed from $60-$ $240^{\circ} \mathrm{C}$ at $3^{\circ} \mathrm{C} / \mathrm{min}$; carrier gas, helium at $1 \mathrm{~mL} / \mathrm{min}$; injection, $0.2 \mu \mathrm{L}$ (10\% hexane solution); split ratio, 1:30. Identification of the constituents was based on comparison of the retention times with those of authentic samples, comparing their linear retention indices relative to the series of $n$-hydrocarbons, and on computer matching against commercial and homemade library mass spectra built up from pure substances and components of known oils and MS literature data $[17,18]$.

\section{RESULTS}

Cultures yielded Penicillium funiculosum and Mucor racemosus. Identification based on morphological features was confirmed by PCR and sequencing for both cultured fungi. The composition of EOs examined is shown in Tables 1 and 2 .

The MIC values of effective EOs were higher against $P$. funiculosum, than $M$. racemosus, with the exception of C. citratus. O. vulgare EO presented consistent antifungal activity against both fungal species tested, followed in descending order by S. sclarea, C. citratus (against M. racemosus) and O. basilicum (against P. funiculosum), T. vulgaris and $S$. aromaticum. Other oils showed lower antigrowth effect, while C. paradisi and C. limon were not active. Detailed MIC data for both fungal species are presented in Table 3.

All mixtures showed antifungal activity at lower concentration with respect to MIC values of each EO not in combination. In particular, M2 appeared to be the most effective, providing MIC values of $0.5 \%$ and $0.25 \%$ against $P$. funiculosum and $M$. racemosus, respectively. FICI indicated that all the components of M2 had a synergistic effect for both fungi $(<0.5)$. EOs mixtures had a fungistatic activity at the above-reported MIC values in all cases.

Regarding the chemical composition of EOs used in the present study, the most abundant components of $O$. vulgare oil were carvacrol and p-cymene. S. sclarea was rich in linalool acetate, while neral and geranial represented the main constituents of $C$. citratus EO. O. basilicum was characterized by high content of linalool and eugenol. Thymol and p-cymene were the prevailing molecules present in T. vulgaris, and anethol was the predominant compound recognized in S. aromaticum.

\section{DISCUSSION}

Fungal spoilage is a process causing sensory changes that can make foods unacceptable for human consumption, and may pose severe health concerns. The present study is the first to describe the setting up of essential oils (EOs) mixtures versus two spoiling moulds cultured from rinds of Marzolino, a typical Italian fresh pecorino cheese.

The results obtained are in agreement with the findings of Felšöciová et al. [19], reporting the activity of $O$. vulgare EO against Penicillium spp. in vitro. Those Authors reported a fungicidal activity of this EO, while in the current study the effect was fungistatic. Kazemi et al. [20] evaluated the effect of O. vulgare against Mucor sp., referring to a good antifungal activity.

The antifungal effectiveness of S. sclarea (MIC 1.25\%) and $O$. basilicum EOs (MICs $1.25 \%$ and 2.5\%) represents an interesting finding, confirming the data provided by Azizkhani et al. [21] against Aspergillus flavus. Conversely, Yousefzadi et al. [22] and Cenci et al. [23] did not report antifungal activity of $S$. sclarea versus Aspergillus niger and Penicillium sp., respectively. C. citratus showed a good antimycotic effect against Penicilli in food [10,24], and it is reported to strongly inhibit Rhizopus stolonifer [25], a mould taxonomically related to Mucor.

Surprisingly, in this study T. vulgaris did not yield a marked antimycotic activity, in contrast with reports from literature $[24,26,27]$. 
Table 1. Chemical composition of investigated essential oils (EOs). Compounds present at less than $1.0 \%$ were not encountered

\begin{tabular}{|c|c|c|c|c|c|c|c|c|c|c|c|c|c|c|c|c|c|c|}
\hline & Component & Class* & LRI & $0 . v$ & 0.6 & F.v & $T . v$ & I.v & S.a & S.s & $0 . m$ & R.o & C.a & C. $p$ & C.I & C.s & C. $b$ & C.c \\
\hline 1 & tricyclene & $\mathrm{mh}$ & 926 & & & 8.6 & & 1.4 & & & & & & & 1.9 & & 1.1 & \\
\hline 2 & a-pinene & $\mathrm{mh}$ & 940 & & & & & & & & & 37.9 & & & & & & \\
\hline 3 & camphene & $\mathrm{mh}$ & 953 & & & & & & & & & 5.4 & & & & & & 1.1 \\
\hline 4 & sabinene & $\mathrm{mh}$ & 976 & & & & & & & & 3.2 & & & & 2.3 & & 1.1 & \\
\hline 5 & $\beta$-pinene & $\mathrm{mh}$ & 980 & & & 1 & & & & & & 5 & & & 11.9 & & 5.4 & \\
\hline 6 & 6-methyl-5-hepten-2-one & $\mathrm{nt}$ & 985 & & & & & & & & & & & & & & & 1.8 \\
\hline 7 & myrcene & $\mathrm{mh}$ & 991 & 2.2 & & & & & & & 1.6 & 1.6 & 1.9 & 2.2 & 1.8 & 2.3 & 1 & \\
\hline 8 & a-phellandrene & $\mathrm{mh}$ & 1005 & & & 2.2 & & & & & & & & & & & & \\
\hline 9 & a-terpinene & $\mathrm{mh}$ & 1018 & 2.1 & & & & & & & 4.7 & & & & & & & \\
\hline 10 & o-cymene & $\mathrm{mh}$ & 1026 & & & & & & & & & 1.1 & & & & & & \\
\hline 11 & p-cymene & $\mathrm{mh}$ & 1026 & 9.3 & & 1.9 & 15.3 & & & & 4.2 & & & & & & & \\
\hline 12 & limonene & $\mathrm{mh}$ & 1031 & & & 6.5 & & 3.9 & & & 2.1 & 3.3 & 94.7 & 92.2 & 65.7 & 95.5 & 33.2 & 2 \\
\hline 13 & $\beta$-phellandrene & $\mathrm{mh}$ & 1031 & & & & & & & & & & & & & & & \\
\hline 14 & 1,8-cineole & om & 1033 & & 5.9 & & & & & & & 22 & & & & & & \\
\hline 15 & (Z) $\beta$-ocimene & $\mathrm{mh}$ & 1040 & & & & & & & & & & & & & & & \\
\hline 16 & (E) $\beta$-ocimene & $\mathrm{mh}$ & 1050 & & & & & & & & & & & & & & & \\
\hline 17 & $\gamma$-terpinene & $\mathrm{mh}$ & 1062 & 5.3 & & & 2.9 & & & & 7.9 & & & & 9.3 & & 6.4 & \\
\hline 18 & cis-sabinene hydrate & om & 1068 & & & & & & & & 3.2 & & & & & & & \\
\hline 19 & cis-linalool oxide (furanoid) & om & 1074 & & & & & & & 2.2 & & & & & & & & \\
\hline 20 & fenchone & om & 1087 & & & 20.1 & & & & & & & & & & & & \\
\hline 21 & terpinolene & $\mathrm{mh}$ & 1088 & & & & & & & & 1.5 & & & & & & & \\
\hline 22 & trans-linalool oxide (furanoid) & om & 1088 & & & & & & & 1.8 & & & & & & & & \\
\hline 23 & trans-sabinene idrato & om & 1097 & 1.8 & & & 3.8 & & & & 12.8 & & & & & & & \\
\hline 24 & linalool & om & 1098 & & 46 & & & & & 8.1 & & & & & & & 14.2 & 1.5 \\
\hline 25 & cis-rose oxide & om & 1111 & & & & & & & & & & & & & & & \\
\hline 26 & camphor & om & 1143 & & & & & & & & & 7.6 & & & & & & \\
\hline 27 & menthone & om & 1154 & & & & & & & & & & & & & & & \\
\hline 28 & isomenthone & om & 1164 & & & & & & & & & & & & & & & \\
\hline 29 & borneol & om & 1165 & & & & 1.6 & & & & & 2 & & & & & & \\
\hline 30 & 4-terpineol & om & 1177 & & & & 2.4 & & & & 17.6 & & & & & & & \\
\hline 31 & a-terpineol & om & 1189 & & & & & & & & 2.7 & & & & & & & \\
\hline 32 & unknown & & & & & & 1.7 & & & & & & & & & & & \\
\hline 33 & menthyl chavicol(=estagol) & $\mathrm{pp}$ & 1195 & & 1.1 & 8.6 & & & & & & & & & & & & \\
\hline 34 & citronellol & om & 1228 & & & & & & & & & & & & & & & \\
\hline 35 & thymol methyl ether & om & 1232 & & & & 1.7 & & & & & & & & & & & \\
\hline 36 & neral & om & 1240 & & & & & & & & & & & & & & & 35.2 \\
\hline 37 & geraniol & om & 1255 & & & & & & & & 2.7 & & & & & & & 4.4 \\
\hline 38 & linalool acetate & om & 1257 & & & & & & & 54.7 & 3.2 & & 1.4 & & & & 31.7 & \\
\hline 39 & (E) cinnamaldehyde & $\mathrm{nt}$ & 1266 & & & & & & & & & & & & & & & \\
\hline 40 & geranial & om & 1270 & & & & & & & & & & & & 1.2 & & & 38.4 \\
\hline 41 & citronellyl formate & om & 1280 & & & & & & & & & & & & & & & \\
\hline 42 & (E) anethol & $\mathrm{pp}$ & 1283 & & & 46.9 & & 89.8 & & & & & & & & & & \\
\hline 43 & Isobornyl acetate & om & 1285 & & 1.6 & & & & & & & 3.3 & & & & & & \\
\hline 44 & bornyl acetate & om & 1285 & & & & & & & & & & & & & & & \\
\hline 45 & thymol & om & 1290 & & & & 52.6 & & & & & & & & & & & \\
\hline 46 & geranyl formate & om & 1298 & & & & & & & & & & & & & & & \\
\hline 47 & carvacrol & om & 1298 & 65.9 & & & & & & & 20.8 & & & & & & & \\
\hline 48 & unknown & & & & & & & & & 5.6 & & & & & & & & \\
\hline 49 & unknown & & & & & & & & & 7.2 & & & & & & & & \\
\hline 50 & a-limonene diepoxide & om & 1347 & & & & & & & 8.6 & & & & & & & & \\
\hline
\end{tabular}


Table 1. Chemical composition of investigated essential oils (EOs) (Continuation)

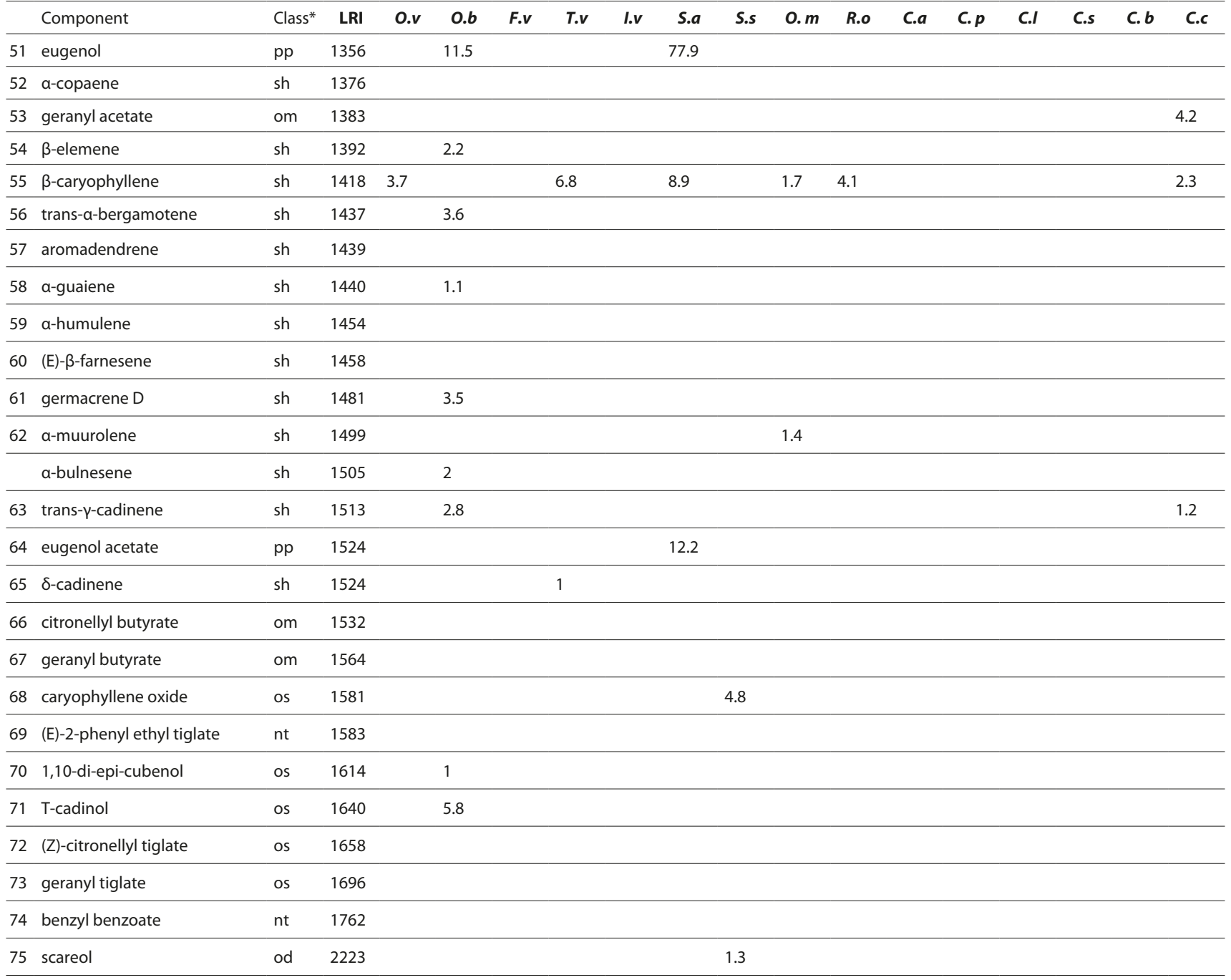

*mh - monoterpene hydrocarbons; om - oxygenated monoterpenes; sh - sesquiterpene hydrocarbons; os - oxygenated

Sesquiterpenes; od - oxygenated diterpenes; $\mathrm{nt}$ - non-terpene derivatives; $\mathrm{pp}$ - phenylpropanoids.

RI-Linear Retention Index.

O.v. - Origanum vulgare; O.b. - Ocimum basilicum; F.v. - Foeniculum vulgare; T.v. - Thymus vulgaris; I.v. - Illicium verum; S.a. - Syzygium aromaticum; S.s. - Salvia sclarea; O.m. - Origanum majorana;

R.o. - Rosmarinus officinalis; C.a. - Citrus aurantium

C.p. - Citrus paradisi; C.I. - Citrus limon; C.s. -itrus sinensis; C.b. -itrus bergamia; C.c. -ymbopogon citratus.

Table 2. Groups of chemical compounds of investigated essential oils (EOs)

\begin{tabular}{|c|c|c|c|c|c|c|c|c|c|c|c|c|c|c|c|}
\hline & $0 . v$ & $0 . b$ & F.v & $T . v$ & I.v & S.a & S.s & O. $m$ & R.o & C.a & C. $p$ & C.I & C.s & C. $b$ & C.c \\
\hline Monoterpene hydrocarbons & 22.5 & 2.3 & 22.1 & 21.5 & 7.3 & & & 27.7 & 56.5 & 97.4 & 96.2 & 94.3 & 98.7 & 49 & 3.9 \\
\hline Oxygenated monoterpene & 71.2 & 56.1 & 21.1 & 64.1 & 0.7 & & 78.2 & 66.6 & 36.7 & 1.9 & 0.5 & 3.6 & 0.6 & 48.4 & 86.3 \\
\hline Oxigenated sesquiterpene & 0.4 & 7.9 & & & 0.1 & 0.4 & 4.9 & 0.4 & 0.3 & & & & & & 0.9 \\
\hline Oxygenated diterpene & & & & & & & 1.3 & & & & & & & & \\
\hline Non-terpene derivatives & 0.1 & & 0.9 & 0.8 & 0.1 & & 0.8 & 0.1 & & 0.5 & 0.6 & 0.1 & 0.7 & 0.1 & 2 \\
\hline Phenylpropanoids & 0.1 & 12.7 & 55.6 & & 90.7 & 90.1 & & & & & & & & & \\
\hline unknown & & 0.2 & & 1.7 & & & 13.9 & & 0.1 & & & & & & \\
\hline Total $^{\mathbf{a}}$ & 98.5 & 99.2 & 99.7 & 97.3 & 100 & 100 & 100 & 98 & 98 & 100 & 99.2 & 100 & 100 & 100 & 97.6 \\
\hline
\end{tabular}

O.v. - Origanum vulgare; O.b. - Ocimum basilicum; F.v. - Foeniculum vulgare; T.v. - Thymus vulgaris; I.v. - Illicium verum;

S.a. - Syzygium aromaticum; S.s. - Salvia sclarea; O.m. - Origanum majorana; R.o. - Rosmarinus officinalis;

C.a. - Citrus aurantium; C.p. - Citrus paradisi; C.I. - Citrus limon; C.s. - Citrus sinensis; C.b. - Citrus bergamia

C.c. - Cymbopogon citratus.

${ }^{a}$ All identified compounds were used for calculating the total percentage of each class of constituents. 
Table 3. MIC* values of tested essential oils vs. Penicillium funiculosum and Mucor racemosus, expressed as percentage

\begin{tabular}{lcc} 
& P. funiculosum & M. racemosus \\
\hline Origanum vulgare & 1 & 1.25 \\
\hline Ocimum basilicum & 1.25 & 2.5 \\
\hline Foeniculum vulgare & 2.5 & 5 \\
\hline Thymus vulgaris & 2.5 & 2.5 \\
\hline Illicium verum & 5 & 2.5 \\
\hline Syzygium aromaticum & 2.5 & 2.5 \\
\hline Salvia sclarea & 1.25 & 1.25 \\
\hline Origanum majorana & $>5$ & 2.5 \\
\hline Rosmarinus officinalis & 5 & 2.5 \\
\hline Citrus aurantium & $>5$ & 5 \\
\hline Citrus paradisi & $>5$ & $>5$ \\
\hline Citrus limon & $>5$ & $>5$ \\
\hline Citrus sinensis & 2.5 & 5 \\
\hline Citrus bergamia & 2.5 & 5 \\
\hline Cymbopogon citratus & 2.5 & 1.25 \\
\hline
\end{tabular}

\begin{tabular}{lcc}
\hline $\begin{array}{l}\text { Syzygium aromaticum, Salvia sclarea, Origanum } \\
\text { vulgare (1\% each) }\end{array}$ & 0.5 & 0.75 \\
\hline $\begin{array}{l}\text { Syzygium aromaticum, Salvia sclarea, } \\
\text { Cymbopogon citratus (1\% each) }\end{array}$ & 0.5 & 0.25 \\
\hline \begin{tabular}{l} 
Cymbopogon citratus, Thymus vulgaris (1.5\% each) \\
\hline
\end{tabular} & 0.75 & 0.75 \\
\hline
\end{tabular}

*MIC - Minimal Inhibitory Concentration

The most significant finding of this present study was the marked synergistic action observed when EOs were tested as mixtures. M2 in particular appeared to be very interesting, showing a good antifungal activity. This feature allowed the use of a very small amount of EOs (0.5\%), with acceptable sensorial properties.

\section{CONCLUSIONS}

In conclusion, the results of the present study showed that S. aromaticum, S. sclarea and C. citratus EOs are characterized by a good antifungal activity, strongly enhanced when combined as a mixture. However, considered that these EOs can be added as natural flavourings in food, further research beyond the present work will be needed to evaluate the organoleptic effects following the application of these natural products in treating cheese rinds.

\section{REFERENCES}

1. Ministero delle politiche agricole alimentari e forestali:_https://www. politicheagricole.it/flex/cm/pages/ServeBLOB.php/L/IT/IDPagina/309 (access: 2017.11.22).

2. Holley RA, Patel D. Improvement in shelf-life and safety of perishable foods by plant essential oils and smoke antimicrobials. Food Microbiol. 2005; 22: 273-292.

3. Seow YX, Yeo C, Chung HL, Yuk HG. Plant Essential Oils as Active Antimicrobial Agents. Crit Rev Food Sci Nutr. 2014; 54: 625-644.

4. Khan A, Ahmad A, Akhtar F, Yousouf S, Xess I, Khan LA, Manzoor N. Ocimum sanctum essential oil and its active principles exert their antifungal activity by disrupting ergosterol biosynthesis and membrane integrity. Res Microbiol. 2010; 161: 816-823.

5. Zabka M, Pavela R. Antifungal efficacy of some natural phenolic compounds against significant pathogenic and toxinogenic filamentous fungi. Chemosphere. 2013; 93(6):1051-1056.

6. Mahboubi M. Artemisia sieberi Besser essential oil and treatment of fungal infections. Biomed. Pharmacother. 2017; 89: 1422-1430.

7. Nikkhah M, Hashemi M, Habibi Najafi MB, Farhoosh R. Synergistic effects of some essential oils against against fungal spoilage on pear fruit. Int J Food Microbiol. 2017; 18: 285-294.

8. Leja KB, Czaczyk K. The industrial potential of herbs and spices - a mini review. Acta Sci Pol Technol Aliment. 2016; 15: 353-365.

9. Liu Q, Meng X, Li Y, Zhao CN, Tang GY, Li HB. Antibacterial and antifungal activity of spices. Int J Mol Sci. 2017; 16: 18.

10. Sessou P, Farougou S, Ahounou S, Hounnankpon Y, Azokpota P, Youssao I, Sohounhloue D. Comparative study of antifungal activities of six selected essential oils against fungal isolates from cheese wagashi in Benin. Pak J Biol Sci. 2013; 16: 1751-1757.

11. Gandomi H, Misaghi A, Basti AA, Bokaei S, Khosravi A, Abbasifar A, Javan AJ. Effect of Zataria multiflora Boiss. Essential oil on growth and aflatoxin formation by Aspergillus flavus in culture media and cheese. 2009; 47: 2397-2400.

12. Samson RA, Hoekstra ES, Frisvad JC, Filtenborg O. Introduction to FoodBorne Fungi, 7th ed. Baarn: Centraalbureau voor Schimmelcultures, 2004.

13. Hong SB, Kim DH, Lee M, Baek SY, Kwon SW, Houbraken J, Samson RA. Zygomycota associated with traditional meju, a fermented soybean starting material for soy sauce and soybean paste. J Microbiol. 2012; 50: $1437-1493$.

14. Boysen ME, Jacobsson KG, Schnürer J. Molecular identification of species from the Penicillium roqueforti group associated with spoiled animal feed. Appl Environ Microbiol. 2000; 66: 1523-1526.

15. Clinical and Laboratory Standard Institute (CLSI). Reference method for broth dilution antifungal susceptibility testing of filamentous fungi. Approved standard M38-A2. Wayne, Pennsylvania, 2008.

16. Rosato A, Vitali C, De Laurentis N, Armenise D, Milillo MA. Antibacterial effect of some essential oils administered alone or in combination with Norfloxacin. Phytomed. 2007; 14: 727-732.

17. National Institute of Standards and Technology NIST/EPA/NIH Mass Spectral Library, Pc Version 1.7. Perkin Elmer, Norwalk, 1999.

18. Adams RP. Identification of essential oils by capillary gas chromatography/mass spectroscopy. Allured Publishing Corporation, Carol Stream, IL, USA, 2001.

19. Felšöciová S, Kačániová M, Elena Horská E, Vukovic N, Hleba L, Petrová J, Rovná K, Stričík M, Hajduová Z. Antifungal activity of essential oils against selected terverticillate penicillia. Ann Agric Environ Med.2015; 22: 38-42.

20. Kazemi M, Rostami H, Ameri A. The study of compositions and antimicrobial properties of essential oils of Origanum vulgare and Rosmarinus officinalis on human pathogens. Curr Res Bacteriol. 2012; 5: $1-12$.

21. Azizkhani, M, Tooryan F, Azizkhani M. Inhibitory potential of Salvia sclarea and Ocimum basilicum against chemical and microbial spoilage in cheese. J Food Saf. 2015; 36: 109-119.

22. Yousefzadi M, Sonboli A, Ebrahimi SH, Hashemi SH. Antimicrobial activity of essential oil and major constituents of Salvia chloroleuca. Z Naturforsch 2008; 63: 337-340.

23. Cenci AM, Ugalde ML, Juliana Steffens J, Valduga E, Cansian RL, Toniazzo G. Control of Penicillium sp. on the surface of Italian salami using essential oils. Food Technol Biotechnol. 2015; 53: 342-347.

24. Nguefack J, Dongmo JB, Dakole CD, Leth V, Vismer HF, Torp J, Guemdjom EF, Mbeffo M, Tamgue O, Fotio D, Zollo PH, Nkengfack AE. Food preservative potential of essential oils and fractions from Cymbopogon citratus, Ocimum gratissimum and Thymus vulgaris against mycotoxigenic fungi. Int J Food Microbiol. 2009; 131: 151-156.

25. Abdulazeez MA, Abdullahi AS, James BD. Essential oils in food preservation, flavor and safety. Publisher Academic Press, 2016.

26. Zantar S, Yedri F, Mrabet R, Laglaoui A, Bakkali M, Zerrouk MH. Effect of Thymus vulgaris and Origanum compactum essential oils on the shelf life of fresh goat cheese. J Ess Oil Res. 2014; 26: 76-84.

27. De Lira Mota KS, de Oliveira Pereira F, de Oliveira WA, de Oliveira Lima I, de Oliveira Lima E. Antifungal activity of Thymus vulgaris L. essential oil and its constituent phytochemicals against Rhizopus oryzae: interaction with ergosterol. Molecules. 2012; 17: 14418-14433. 